\title{
Análise do Trabalho Prisional: um Estudo Exploratório
}

\author{
Ana Margarete Lemos \\ Cláudio Mazzilli \\ Luís Roque Klering
}

\section{ResUMO}

O estudo, baseado em pesquisa de natureza exploratório-descritiva, busca identificar fatores do atual modelo de trabalho prisional do Rio Grande do Sul que dificultam a promoção da ressocialização de apenados. Concomitantemente, propõe mudanças na sua concepção como estratégia, para o atingimento de índices mais expressivos de ressocialização. Os dados foram coletados por meio de consultas aos prontuários penais e de entrevistas semi-estruturadas com vinte apenados do sistema penitenciário gaúcho. Para a análise dos dados coletados, utilizou-se a metodologia da análise de conteúdo, na modalidade de análise temática. Os resultados são apresentados em cinco categorias finais: o trabalho prisional, a identidade no sistema prisional, a ressocialização idealizada, o trabalho prisional no desenvolvimento pessoal e as condições do trabalho prisional. Detectou-se o desconhecimento por parte da Administração Penitenciária da importância da relação entre prazer, sofrimento e motivação mais ampla no trabalho, para uma construção positiva da identidade dos apenados.

Palavras-chaves: trabalho prisional; ressocialização; organização do trabalho.

\begin{abstract}
In this exploratory-descriptive research, the author looks into the identification of the factors concerning the present work model in Rio Grande do Sul State prisions, Brazil. This criticized model is responsible for the difficulties in promoting a reasonable resocialization of the prisoners. Simultaneously the author suggests important changes in the conquest of a more expressive achievement toward the expected resocialization. Data were collected in examining penal hanbook and references and chiefly by means of semi-structured interviews with twenty prisioners. Collected data were analyzed according to content methodology; results are presented in five final categories: (1) prisonal work; (2) prison system identity; (3) ideological resocialization; (4) prisional work influence on personal growth; (5) prisional work conditions. It was noticed that Penitentiary Administration ignores the importance of a better relation among psychological motivation, suffering and a legitimate pleasure in accomplishing prisonal imposed work, in overcoming huge problems and challenges and in reaching the intended prisioners' resocialization.
\end{abstract}

Key words: resocialization; pleasure and suffering in the work; organization of the work. 


\section{INTRODUÇÃO}

O presente estudo tem como objetivo a análise do trabalho prisional enquanto prática de ressocialização.

Desde que foi criada no Estado do Rio Grande do Sul, a Superintendência dos Serviços Penitenciários - SUSEPE, tem voltado sua atenção para a necessidade de recuperar o indivíduo apenado, oferecendo-lhe meios de reinserção social. Segundo a própria instituição, o trabalho constitui o principal instrumento para atingir a ressocialização dos presos.

Porém o que se observa, pelos dados disponíveis ou que circulam pela sociedade, é que o presídio induz maior violência.

Grande parte da inoperância do atual modelo ressocializador decorre da forma como este é organizado, em relação aos aspectos ligados à divisão do trabalho e à divisão dos homens. Sendo assim, o conhecimento por parte da instituição penitenciária da necessidade de uma organização do trabalho prisional que perpasse pela relação entre prazer e sofrimento no trabalho possibilita a mudança e gera repercussões positivas no processo de ressocialização e, conseqüentemente, na vida egressa dos apenados, bem como na vida daqueles com quem esses se relacionam.

Nosso artigo é dividido em três partes: na primeira parte, procura-se esboçar, por meio do referencial teórico, como se processam as relações entre os indivíduos, como foi introduzido o trabalho prisional nos presídios, quais as relações que o permeiam, o que as administrações penitenciárias em geral pretendem atingir com a sua utilização. Na segunda parte, apresenta-se a metodologia utilizada, no caso a análise de contéudo. Na terceira parte são tecidas considerações acerca dos resultados obtidos, apresentam-se as conclusões decorrentes da análise de contéudo, são ressaltados os limites enfrentados na realização da pesquisa e expõem-se sugestões para novos estudos.

\section{O Significado das Relaçóes de Poder no Trabalho Prisional}

No século XVIII, diversos segmentos da área do direito penal preconizavam tratamento mais humano para as penas. Esses segmentos proclamavam uma forma de amenizar os suplícios e a crueldade a que eram submetidos, nessa época, os 
indivíduos que praticavam crimes. Com o desaparecimento do suplício, surge novo tipo de punição, a privação de liberdade, que coincide com o início da transformação da sociedade feudal em sociedade capitalista.

Segundo Foucault (1975, p. 70), “a passagem dos suplícios para a punição se deu como uma fronteira legítima do poder de punir. $\mathrm{O}$ homem que os reformadores puseram em destaque contra o despotismo do cadafalso é também o homem da medida, não das coisas, mas do poder”.

A nova forma de punição buscava um esforço, para ajustar os mecanismos de poder que enquadram a existência dos indivíduos, ou seja, visava a uma adaptação e harmonização dos instrumentos que se encarregavam de vigiar o comportamento cotidiano das pessoas. Mais do que o respeito pela humanidade dos condenados, buscava-se uma justiça mais desembaraçada e mais inteligente que ensejasse uma vigilância penal mais atenta ao corpo social.

Dessa forma, o verdadeiro objetivo da reforma não era fundamentar uma punição com princípios mais eqüitativos, mas estabelecer uma nova economia do poder de castigar. Assegurava, assim, melhor distribuição desse poder, repartindo-o em circuitos homogêneos, para ser exercido em toda a parte e de maneira contínua em todo o corpo social, tornando o poder de punir mais regular, mais eficaz, mais constante e mais bem detalhado em seus efeitos.

Resumindo, a reforma teria de fazer com que o poder de julgar não dependesse mais de privilégios múltiplos, descontínuos e contraditórios da soberania, mas de efeitos continuadamente distribuídos de poder público. Sua estratégia era inserir mais profundamente no corpo social o poder de punir.

De acordo com Foucault (1975, p. 297), “a prisão foi uma peça essencial no conjunto das punições, marcando um momento importante na história da justiça penal. Fundamentadas nas sociedades industriais, pelo seu caráter econômico, as prisões aparecem como uma reparação. Retirando tempo do condenado, a prisão parece traduzir concretamente a idéia de que o criminoso lesou, não somente a vítima, mas a sociedade inteira. Esse caráter econômico-moral de uma penalidade contabiliza os castigos em dias, em meses, em anos, e estabelece equivalências quantitativas entre delitos e duração das penas".

Mas a prisão também se fundamenta como papel de transformar indivíduos. A prisão deve ser um aparelho disciplinar exaustivo, deve tomar a seu cargo todos os aspectos dos indivíduos: seu treinamento físico, sua aptidão para o trabalho, seu comportamento cotidiano, sua atitude moral, suas disposições, enfim ela dá um poder quase total sobre os detentos.

A disciplina fabrica indivíduos, ela é a técnica específica de um poder que toma 
os indivíduos ao mesmo tempo como objetos e como instrumentos de seu exercício.

Sob a ótica de uma disciplina rígida, foi implantado o trabalho prisional. Utilizado como princípio de ordem e de regularidade, veicula, pelas exigências que the são próprias, de maneira insensível, as formas de um poder rigoroso, sujeita os corpos a movimentos regulares, exclui a agitação e a distração, impõe uma hierarquia e uma vigilância que serão ainda mais bem aceitas, e penetrarão com mais profundidade no comportamento dos apenados.

Portanto, de acordo com Foucault (1989, p. 33), “o grau de utilidade que é dado ao trabalho prisional, desde sua origem nas execuções das penas, não é do lucro ou de uma habilidade útil; mas a constituição de uma relação de poder, criando um mecanismo de submissão individual e de ajustamento a um aparelho de produção".

À luz desse entendimento, se pode aferir que o trabalho prisional, desde a sua origem, está ligado diretamente à concepção taylorista de organização do traba1ho. Segundo Rago e Moreira (1984, p. 25), "o taylorismo, enquanto método de organização científica da produção, mais do que uma técnica de produção, é essencialmente uma técnica social de dominação". Ao organizar o processo de trabalho, ao dividir o trabalho de concepção e o de execução, ao estruturar as suas relações, e ao distribuir, individualizadamente, a força de trabalho, a organização consegue impor o seu controle e o seu poder.

O trabalho prisional, ora desenvolvido nas instituições penitenciárias, segue estritamente os princípios do taylorismo. Isso porque está voltado para o controle dos apenados, privilegiando uma rígida disciplina, e é totalmente prescrito e normatizado pela Lei de Execuções Penais - LEP, a qual prescreve quem deve trabalhar e como esse trabalho tem de ser desenvolvido.

E, atualmente, é de acordo com essas normas e prescrições que a instituição penitenciária deve administrar o trabalho prisional. Utilizando métodos e processos que reproduzem a lógica da dominação e da disciplina que, mesmo contrariando o discurso institucional, constitui de fato o objetivo principal da execução da pena.

Nesse sentido, a instituição penitenciária reveste-se do papel de uma empresa, utilizando, para alcançar seus fins, os meios de coerção necessários para manter a dominação sobre os apenados. Meios esses que, segundo Pagés et al. (1992, p. 28), "se denominam processo de mediação, e esse processo é colocado como a aliança das restrições da empresa e os privilégios oferecidos aos indivíduos".

Os privilégios funcionam como um termo que vem ocultar a contradição entre 
os objetivos da empresa, os do sistema capitalista, o lucro e a dominação, que no caso dos presídios, volta-se mais para a questão da dominação, e os objetivos dos trabalhadores. Existem diferentes tipos de mediação, porém a que mais diz respeito à condição do apenado em sua relação com a instituição é a mediação em nível psicológico, onde a dupla privilégio-restrições se transforma em dupla prazerangústia. A angústia provocada pela onipresença dos controles, pelo caráter ilimitado e inatingível das exigências, é compensada pelos privilégios que o presídio pode oferecer aos apenados, ou seja, à medida que os apenados atenderem às exigências do padrão de comportamento prisional, podem obter benefícios, tais como: redução da pena (a cada três dias de trabalho o apenado diminui um dia de sua pena); troca de regime; direito a visitas íntimas; e, outros privilégios que, no jogo do poder, a instituição pode oferecer para atingir seus objetivos. Portanto, através da mediação psicológica a instituição penitenciária encontra um sistema coerente, orientado para a subordinação e para o enquadramento do indivíduo no seio de uma ordem global definida.

Desta forma, o trabalho prisional ocupa os apenados e é a medida correta contra os desvios de sua imaginação, constituindo uma relação de poder, um esquema de submissão individual e um ajustamento a um aparelho de produção. Mantendo a ordem e a disciplina garante-se uma boa administração, habilitando, dessa forma, a instituição no que tange ao seu sistema de representação.

A criminalidade, muitas vezes, é uma carência de socialização. Sendo assim, a execução penal deve se esforçar em compensar, em cada delinqüente individual, as carências de seus respectivos processos de socialização, possibilitando ao condenado voltar a uma vida que se ajuste à lei, estimulando de todas as maneiras possíveis sua integração na comunidade legal em que faz parte.

Uma das principais vias, para incitar os apenados ao valor do trabalho, passa, obrigatoriamente, pela percepção do indivíduo na sua totalidade, ou seja, de reconhecer o apenado como um ser biológico, psíquico e social capaz de ser ator de sua própria história e de fixar seus limites.

\section{O Trabalho como Fator Ressocializante}

A partir da reforma do sistema penal, no século XVIII, foi introduzido o trabalho nas prisões como fator punitivo. Essa nova forma de punição não previa a reeducação dos delinqüentes. Pelo contrário, ela servia como mecanismo de manutenção da nova ordem social vigente, uma vez que, segundo Melossi (1987, p. 170), "através da rígida disciplina de trabalho impingida às prisões, 
pretendia-se o adestramento do proletariado com a finalidade de que, quando saíssem em liberdade, aceitassem as condições de trabalho que lhes eram oferecidas, permitindo, dessa forma o máximo de extração de mais-valia".

No fim do século XVIII e início do século XIX, começa-se a repensar a problemática da execução penal, surgindo novos modelos de conduta referentes à privação da liberdade, o que originou os sistemas penitenciários (Wolff, 1990). Destacam-se o Sistema da Filadélfia, o Sistema Panóptico, o Sistema de Auburn e os progressivos, onde cada um possuía diferentes entendimentos para a questão do trabalho prisional.

Os sistemas progressivos pretendiam uma administração carcerária voltada para a humanização e não para a punição. Sua base era a concessão de marcas ou vales no caso de os apenados apresentarem bom comportamento, o qual era definido pelo trabalho e disciplina; se, pelo contrário, os apenados apresentassem uma conduta censurável, eram retiradas as marcas ou vales. Essas marcas ou vales representavam uma flexibilidade nas penas, o que poderia acelerar sua liberdade. A influência desse sistema penal marca a maioria dos códigos penais e de execução de penas da atualidade.

Objetivando manter controle total sobre os apenados, o sistema penitenciário submetia a condições sub-humanas todos os indivíduos que infringissem as normas sociais, não importando se esses apenados fossem adultos ou crianças. Dentro das fronteiras institucionais, a condição de indivíduo, de ser social, desaparecia e, conseqüentemente, o tratamento penal voltava-se, exclusivamente, para o sofrimento, para a humilhação e para a degradação.

No Brasil, o trabalho prisional como forma de punição e controle sobre os indivíduos predominou desde a época do império até 1937, quando passou a haver preocupação por parte dos juristas e penitenciaristas em instituir uma lei específica para a execução penal. Segundo Alencar (apud Wolff, 1990), uma comissão foi formada por juristas que elaboraram o primeiro anteprojeto do Código Penitenciário da República, que não chegou a ser aprovado, devido à vigência do Estado Novo em 1937. O anteprojeto inovava diversos aspectos da execução penal, prevendo que as atividades produtivas teriam como objetivo o ressarcimento dos custos da prisão, servindo também como meio de educação profissional e de readaptação social dos condenados.

Em 1951, a ONU (apud Revista do Sistema Penitenciário, 1973) assumiu os trabalhos referentes ao tratamento de apenados, durante a execução de suas penas, e no ano de 1955, em Genebra, foram aprovadas, no I Congresso das Nações Unidas sobre Prevenção e Tratamento do Delinqüente, as Regras Mínimas para o Tratamento de Presos, sendo posteriormente recomendada sua apro- 
vação pelo Conselho Econômico e Social, o que ocorreu pela Resolução 663 CI de 31 de julho de 1957. As Regras Mínimas da ONU não dispõem sobre os sistemas penitenciários, mas sugerem procedimentos no que tange ao tratamento penal, os quais influenciaram a legislação e normatização de alguns serviços penitenciários, destinados a assegurar garantias judiciais e a humanização das prisões.

Sob essa ótica, criou-se em 1968, no Estado do Rio Grande do Sul, a Superintendência dos Serviços Penitenciários. Órgão eminentemente voltado para a busca da ressocialização do apenado, distinguindo-se dos demais sistemas do país por ser um regime penitenciário, e não carcerário, cuja principal diferença reside no fato de o regime carcerário voltar-se apenas para a guarda do preso, sem a preocupação de reintegrá-lo na sociedade, enquanto o regime penitenciário se volta para a recuperação do indivíduo apenado, visando à sua adaptação na sociedade. E, para promover a ressocialização do preso, buscou no trabalho prisional seu principal instrumento.

Observa-se que, desde que se extinguiram os suplícios como forma de punição até a atualidade, o trabalho prisional passou a exercer papel predominante na execução penal, dentro das sociedades capitalistas. E esse fato pode estar ligado à própria concepção que se tem do trabalho como um todo.

Nas organizações, em que o trabalho é repetitivo e sob pressão, não há lugar para atividades fantasiosas; desta forma, a energia psíquica se acumula, transformando-se em fonte de tensão e desprazer. Por outro lado, as organizações que oferecem um campo de ação, um terreno, onde o trabalhador concretiza suas aspirações, suas idéias, sua imaginação e seus desejos, possibilitam ao trabalhador encontrar fonte de prazer e satisfação.

O trabalho prisional por exigências que lhe são próprias desde sua concepção até os nossos dias, se enquadra perfeitamente no primeiro tipo de organização: qualquer tipo de iniciativa por parte dos apenados é imediatamente tolhida em nome do binômio segurança/disciplina, o que inviabiliza qualquer forma de envolvimento efetivo do apenado com o trabalho.

Dessa maneira, o sistema penitenciário, como instituição total, afirma sua preocupação com a reintegração dos indivíduos à sociedade, mas exerce uma relação única de subordinação; atuando como reificador da instituição, massifica a condição do apenado.

Por outra, a instituição penitenciária utiliza o trabalho prisional como estratégia de ressocialização, mas parece esquecer que uma estratégia focaliza finalidade e ação concreta como forma de se autodefinir como sistema pragmático e não teórico. Ao mesmo tempo, a estratégia está atenta às possibilidades de desenvol- 
vimento e às formas de promovê-lo. E somente uma ação concreta pode promover as transformações no processo de desenvolvimento visando a atingir um objetivo determinado (Gaj, 1990).

Portanto, para que o trabalho prisional realmente constitua uma estratégia de ressocialização, deve-se basear em ações concretas, e não somente num discurso ideológico; deve levar em conta, principalmente, os aspectos referentes ao desenvolvimento pessoal dos apenados, utilizando e aprimorando sua capacidade de percepção, bem como suas habilidades, para a resolução de problemas complexos e de serem criativos e inovadores, dentro de um processo real de trabalho.

\section{A Função das Superintendências dos Serviç̧os Penitenciários}

A SUSEPE tem como incumbência planejar e executar a política penitenciária do Estado, vindo a substituir os extintos Departamento dos Institutos Penais, Comissão de Reaparelhamento Penitenciário e Serviço Social Penitenciário que, até então, eram os responsáveis pelo tratamento dos apenados no Rio Grande do Sul.

Sob essa ótica, o então Governador do Estado Walter Perachi Barcellos, sancionou a Lei ${ }^{\circ} 5.745$, de 28 de dezembro de 1968, que dispõe sobre a estrutura da Superintendência dos Serviços Penitenciários da Secretaria do Interior e Justiça, regula seu funcionamento e dá outras providências.

O Decreto $\mathrm{n}^{\circ} 20.768$, de 7 de dezembro de 1970, reorganizou a estrutura da SUSEPE, ficando assim definida: sua finalidade era o planejamento e a execução da política penitenciária do Estado e, assim, devia promover a reeducação do delinqüente, com vistas à sua recuperação social, por meio da execução administrativa das penas privativas da liberdade.

Como órgão de apoio administrativo, a Unidade de Administração deveria executar as atividades de administração geral da Superintendência relativas ao pessoal, ao material, aos processos, aos serviços gerais, à administração financeira, à contabilidade e à auditoria.

Como órgão de atividade-fim, o Departamento de Estabelecimentos Penais teria de dirigir e coordenar o funcionamento dos estabelecimentos da rede penitenciária, assegurando as condições legais para a execução administrativa das penas privativas da liberdade; fazer cumprir normas de ação uniformes ou diferenciadas aos estabelecimentos, no tocante à ordem, segurança e atividades, e exercer fiscalização em todos os setores e serviços dos estabelecimentos da rede penitenciária. 


\section{Metodologia de Pesquisa}

Nosso estudo é caracterizado como pesquisa exploratório-descritiva no Sistema Penitenciário Gaúcho. Este tipo de estudo visa a obter e a analisar as características e opiniões de populações de pequenas amostras, que se presumem representativas dessas populações. Dessa forma, foi utilizada a análise de conteúdo como base de sua metodologia, haja vista esta constituir, de acordo com Bardin (1977), um conjunto de técnicas de análise de comunicações, que contêm informação sobre o comportamento humano atestado por fonte documental.

\section{Delimitação da População da Pesquisa}

Os apenados integrantes da amostra fazem parte de dois presídios de Porto Alegre, selecionados de acordo com o tipo de regime de execução da pena, sendo um com regime de condenação fechado, e o outro com regime de condenação aberto e semi-aberto. Os apenados que compõem a amostra foram selecionados pelo tipo de crime pelo qual foram condenados. Nessa categoria, foram selecionados vinte apenados, sendo catorze condenados por crimes de homicídio simples e seis condenados por crime de estelionato.

O número de apenados em cada tipo de crime não obedeceu a qualquer tipo de critério pré-estabelecido, baseando-se apenas na vontade dos apenados em participarem das entrevistas. A escolha do tipo de crime deve-se ao fato de que, no caso de homicídio simples, conforme o caput do Art. 121 do Código Penal Brasileiro, o apenado cometeu o crime de matar alguém, não apresentando características que o qualifiquem, tais como: sem requinte de crueldade, mediante promessa de recompensa. Esse tipo de crime, normalmente, não apresenta reincidência, portanto o apenado é perfeitamente passível de recuperação, desde que se ofereçam condições, para evitar que ele acabe contaminado pelo meio, pelos exemplos de condutas que o levem a se envolver com outros tipos de crimes.

No que tange ao estelionato, o Código Penal Brasileiro, no artigo 171, dispõe que se trata de caso de pessoa que obtém para si, ou para outrem, vantagem ilícita, em prejuízo alheio, induzindo ou mantendo alguém em erro, mediante artifício, ardil, ou qualquer outro meio fraudulento. Portanto trata-se de pessoas que, normalmente, possuem uma inteligência mais aguçada, que podem fornecer maiores subsídios à entrevista. E, ainda, de serem capazes de assimilar com maior facilidade um novo redimensionamento social. 


\section{A Coleta de Dados}

Como instrumento de coleta de dados, foram utilizadas entrevistas semiestruturadas gravadas e, posteriormente, transcritas, com a população que compõe a amostra. A escolha deste tipo de entrevista deve-se à possibilidade que esta oferece em obter do entrevistado indícios dos aspectos mais relevantes do problema, bem como suas descrições da situação em estudo. Mediante uma conversação guiada, pode-se obter informações detalhadas para análise.

Objetivando averiguar a compreensão por parte dos entrevistados das questões realizadas e ainda verificar a eficácia da elaboração do instrumento, para atingir os objetivos da abordagem do estudo, realizaram-se, a título de estudo piloto, duas entrevistas com os apenados, entrevistas estas que fazem parte da amostra final.

\section{A Análise de Dados}

Para facilitar a análise das informações, foi utilizada a categorização que, de acordo com Bardin (1977), constitui operação de classificação dos elementos componentes de um conjunto, por diferenciação e, seguidamente, por reagrupamento segundo o gênero, com critérios previamente definidos. As categorias são rubricas ou classes, as quais reúnem um grupo de elementos sob um título genérico; esse agrupamento se efetua em razão dos caracteres comuns dos elementos e da natureza do fenômeno e do problema.

O estabelecimento das categorias seguiu três pólos cronológicos de análise de conteúdo: a pré-análise; a exploração do material e o tratamento dos resultados; a inferência e a interpretação.

A pré-análise operacionalizou e sistematizou as idéias iniciais, visando à condução de um esquema preciso, para o desenvolvimento das operações seguintes, resultando em indicadores que fundamentam a interpretação final.

Para estabelecer as categorias iniciais da análise, realizou-se uma leitura flutuante do material, viabilizando o conhecimento da estrutura e da narrativa, possibilitando, dessa forma, ter as primeiras orientações e impressões em relação à mensagem dos documentos. A seguir, realizou-se a escolha dos documentos pertinentes à análise. Os critérios de homogeneidade e adequação também foram levados em conta, para a elaboração das categorias iniciais, intermediárias e finais que possibilitaram o aprofundamento da análise.

A fase da análise do material se constituiu na codificação das informações obtidas, isto é, na análise propriamente dita, seguindo os critérios das categorias 
estabelecidas. E, finalmente, na fase de tratamento dos resultados, com inferência e interpretação, os resultados brutos foram ajustados de maneira que fossem significativos e válidos, permitindo a compreensão dos fatores que impedem o atual modelo de trabalho prisional tornar-se, efetivamente, ressocializador.

Como resultado, busca-se apresentar conclusões obtidas pelo processo de sucessivos refinamentos, que se acredita atingir melhor e maior nível de interpretação e compreensão dos fatores que norteiam o atual modelo de trabalho prisional.

\section{Apresentaçāo dos Resultados da Análise de Conteúdo}

Segundo havia sido descrito, os dados das categorias intermediárias foram reagrupados, para atingir novos níveis de compreensão das percepções dos entrevistados, resultando, dessa forma, as categorias finais.

\section{A Categoria Final Trabalho Prisional}

Os apenados entrevistados, ao descreverem como percebem o trabalho prisional, salientam os aspectos inerentes ao seu envolvimento nele, como se processa a sua participação, quais os fatores que mais influenciam a realização de atividades dentro dos presídios. Enfatizam que, acima de qualquer outro motivo, sua participação se deve estritamente à possibilidade de diminuírem a sua pena.

Em raros casos, percebe-se um envolvimento maior dos apenados com o processo produtivo. Entende-se, no entanto, que, se o trabalho prisional fosse organizado de outra maneira, com enriquecimento das tarefas que pudessem proporcionar crescimento individual e, principalmente, se fosse organizado de maneira que gerasse condições de desafio e de satisfação com as tarefas, se possibilitasse aos indivíduos encontrar formas de perseguir seus questionamentos interiores e traçar a sua história, seria elemento mais eficiente, para promover as condições necessárias à ressocialização.

O trabalho prisional é idealizado de maneira que constitua um mecanismo que permita a reeducação dos apenados e o seu conseqüente enquadramento na sociedade. Entretanto, para que um indivíduo possa utilizar o trabalho como um operador fundamental de construção e reestruturação, esse deve reunir as condições propícias para tal. Essas condições passam pela relação de prazer e sofrimento no trabalho.

O real significado do trabalho, na vida dos apenados, só será visualizado a partir do momento em que a organização penitenciária entender que o indivíduo 
só encontra sentido no trabalho, quando pode estabelecer com ele um vínculo que lhe permita uma sintonia entre o significado da tarefa e a sua história singular. $\mathrm{O}$ trabalho somente terá um papel preponderante na ressocialização dos apenados quando esses encontrarem um sentido nas tarefas que realizam e, a partir de então, tentarem buscar o equilíbrio físico e mental.

\section{A Categoria Final A Identidade no Sistema Prisional}

Essa categoria abrange a ampla questão do sofrimento que os apenados referiram em suas entrevistas. Esse sentimento envolve a consciência do processo utilizado pela instituição penitenciária, no sentido de despersonalizá-los, para que, dessa forma, sejam atendidos os preceitos de ordem e disciplina das instituições fechadas.

Os apenados referem, claramente, todo o processo de mortificação do eu a que são submetidos dentro da instituição. E, ainda, a persistência da organização penitenciária em anular uma cultura apreendida na vida pregressa.

A ordem e a disciplina são priorizadas em todos os níveis, dentro dos presídios, até mesmo no trabalho prisional, onde prevalece a preocupação em manter os apenados ocupados, para não terem tempo para pensar, e em torná-los submissos e adequados aos preceitos institucionais.

Porém, dentro desse processo, os apenados tentam encontrar, no trabalho prisional, mecanismos que possibilitem manter algumas características da personalidade anteriormente adquirida.

Portanto a organização do trabalho prisional exerce uma ação efetiva sobre a identidade dos apenados. Isso porque, ao organizar o trabalho de forma predominantemente taylorista, não permite a criação de espaços que possibilitem a construção do sujeito, a conquista da identidade e, dessa forma, anula qualquer tentativa de continuidade e historização do sujeito. Não permitindo a construção e estruturação dos indivíduos, o trabalho prisional, da forma como está sendo desenvolvido, inviabiliza o processo de ressocialização.

\section{A Categoria Final A Ressocialização Idealizada}

Os apenados acreditam que, pelo trabalho prisional, podem adquirir uma nova postura em face ao mundo e, dessa forma podem ser mais bem aceitos pela sociedade. Existe a crença de que o trabalho pode, realmente, gerar condições, para se estruturarem socialmente; mas, por outro lado, estão conscientes de que o atual trabalho prisional somente opera para mantê-los ocupados; há, assim, uma con- 
tradição muito expressiva entre a realidade e a expectativa. Ao mesmo tempo que percebem o trabalho como fator de equilíbrio social, percebem que a maneira como esse se desenvolve não contribuirá para a sua realização. Chegam mesmo a afirmar que o trabalho prisional não é trabalho; é só uma maneira de a instituição manter a ordem e a disciplina.

Entendem que, pelo trabalho, poderiam ressocializar-se; mas, ao mesmo tempo, encaram o trabalho prisional apenas como meio de atingirem mais rapidamente a sua liberdade.

Além disso, a remuneração, que deveria constituir fonte de manutenção da família, o que proporcionaria também um reenquadramento social, é totalmente simbólica dentro dos presídios. A conseqüência de tal fato é o sentimento de rejeição ao trabalho prisional por parte dos apenados.

\section{A Categoria Final O Trabalho no Desenvolvimento Pessoal}

Os apenados demonstram ser necessário um grau de envolvimento mais profundo, com relações mais próximas por parte do corpo funcional e dos próprios apenados, ressentindo-se de um contato mais informal e com uma maior interação, de maneira a dissociá-los do crime e, portanto, de forma a serem tratados como indivíduos portadores de uma história singular e não apenas como criminosos.

Entendem ainda que merecem possibilidades profissionais, que possuem seus desejos e aspirações, que sentem necessidade de reconhecimento das suas potencialidades, que precisam sentir-se envolvidos com as atividades e encontrar sentido nelas, da mesma forma que seus desvios devem ser mais bem compreendidos. Possuem nítida percepção da rejeição da sociedade em relação a sua condição. Mesmo buscando seu reenquadramento social, esta sociedade não está devidamente preparada para recebê-los, e nega a sua existência, pois a ideologia dominante estabelece uma linha de conduta e não permite que os indivíduos se afastem dela.

Portanto os apenados têm a clara conviç̧ão de que a sua ressocialização não depende exclusivamente deles, porquanto a sociedade exerce um papel importante nesse processo, isto é, aceitá-los e proporcionar-lhes uma segunda oportunidade de adequarem-se aos valores sociais.

\section{A Categoria Final Condições do Trabalho Prisional}

De acordo com as entrevistas, não existe nenhum critério de seleção dos apenados para o trabalho; prevalece apenas a preocupação com a disciplina. A instituição 
não empreende maiores esforços para tentar buscar um trabalho em que os apenados possam encontrar significado. E, quando possui um trabalho mais significativo, a instituição se desinteressa pela manutenção e preservação do material de trabalho.

Portanto a forma como o trabalho prisional se operacionaliza atualmente deixa muito a desejar para atingir a ressocialização.

\section{Conclusóes Finals}

$\mathrm{Na}$ categoria do trabalho prisional, foi possível constatar que, desde o fim do século XVIII e início do século XIX, quando se começou a repensar a problemática da execução penal, momento em que surgiram novos modelos de conduta referente à privação da liberdade, em que se originaram os sistemas penitenciários, o trabalho prisional vem exercendo um papel predominante. Já em nosso século, esse papel assume importância capital para a execução penal, à medida que a preocupação dessa se volta mais para a possibilidade de ressocialização do apenado, aparecendo o trabalho prisional como mediador privilegiado, por meio das exigências que lhe são próprias, para o ajustamento dos indivíduos aos padrões sociais. Sob essa ótica, o sistema penitenciário gaúcho passa a utilizar o trabalho prisional como principal veículo de reintegração social.

À luz desse entendimento, pode-se inferir que o trabalho realmente constitui precioso elemento para a reintegração social, à medida que ele é um operador fundamental na própria construção do sujeito e, ainda, um mediador privilegiado, senão único, entre inconsciente e campo social, e entre ordem singular e ordem coletiva. Nessa construção do sujeito, envolvem-se não apenas os aspectos concretos do trabalho, mas também os aspectos simbólicos, como seus desejos, suas aspirações (Dejours, Abdoucheli e Jayet, 1994).

Todo o ser humano e, principalmente, os apenados, deve encontrar no trabalho condições que permitam a busca de seu questionamento interior e traçar a sua história, para que encontrem o equilíbrio necessário ao seu real ajustamento social.

Dessa forma, o trabalho prisional tem de ser organizado de maneira que as tarefas realizadas não representem apenas estímulos mecânicos, mas que, acima de tudo, os apenados encontrem nas condições de trabalho os fatores necessários para o seu desenvolvimento pessoal.

Na categoria da identidade no trabalho prisional, verifica-se que o ser humano 
possui todo um conjunto de representações em relação ao próprio homem, à sociedade e à realidade. Essas representações são herdadas, inicialmente, de seu núcleo familiar e, posteriormente, de todas as suas relações sociais; estas passam a determinar seu comportamento social. Sendo assim, embora o homem seja uma totalidade, a identidade é reatualizada mediante os rituais sociais. O indivíduo não é portador de um único papel, mas o representante de todas as determinações de um indivíduo concreto.

Dessa forma, estabelece-se intrincada rede de representações que permeia todas as relações. Cada identidade reflete outra identidade, desaparecendo qualquer possibilidade de se estabelecer um fundamento originário para cada uma delas. Este jogo de reflexões múltiplas que estrutura as relações sociais é mantido pelas atividades dos indivíduos, de tal forma que se pode dizer que as identidades, no seu conjunto, refletem a estrutura social, ao mesmo tempo que reagem sobre ela, conservando-a ou transformando-a.

Sintetizando, as possibilidades de diferentes configurações de identidade estão relacionadas com as diferentes configurações da ordem social. Dessa forma, o indivíduo que ingressa num estabelecimento prisional possui uma identidade produzida pelas relações do seu meio social, onde ele possui uma cultura aparente, uma concepção de si mesmo. Quando há seu ingresso numa prisão, segundo Goffman (1974), inicia-se uma série de rituais, de humilhações, de degradação, de profanação do eu. O seu eu começa a ser mortificado, começam uma série de mudanças radicais em sua carreira moral; o apenado acaba descobrindo que perdeu alguns de seus papéis que mantinha no mundo exterior.

O trabalho prisional deveria funcionar como atenuante nesse processo de mortificação. A instituição penitenciária, embora apresente as características de instituição total, deveria preocupar-se mais com a possibilidade de fazer com que o indivíduo apenado encontre uma nova identidade, cujo reflexo provenha de um meio social ajustado, onde o trabalho passe a ser concebido como fator gerador de inúmeras possibilidades de desenvolvimento pessoal e, conseqüentemente, de uma identidade social.

$\mathrm{Na}$ categoria da ressocialização idealizada, podemos ressaltar que, embora o trabalho prisional constitua, segundo a ótica da execução penal, o principal mecanismo para atingir a ressocialização do apenado, a forma como ele se organiza está muito longe de atingir seus objetivos. Atualmente, o modelo utilizado de trabalho prisional não tem capacidade de gerar nos apenados uma conscientização do papel estruturante que ele possui. Segundo Dejours, Dessors e Desriaux (1993), desenvolver uma atividade é um ato imprescindível para as pessoas, mesmo que esse trabalho se baseie nos princípios tayloristas, que o vêem como algo parcelar e especializado, pois o ato de trabalhar está diretamente ligado à sobrevivência 
dos indivíduos e ao seu condicionamento social. Por meio da atividade profissional, o indivíduo não somente obtém um modo de ganhar a vida, mas também encontra um meio de inserção social. Assim, o trabalho possui o poder de estruturar indivíduos, tanto em face à saúde mental quanto à saúde física, e portanto se enquadra perfeitamente como um operador fundamental para a promoção da ressocialização dos apenados.

Por outro lado, um trabalho que não ofereça grande coisa que fazer, como é o caso específico do trabalho prisional (mas que é preciso estar presente e fazer de conta que se está ocupado), pois as necessidades de envolvimento dos apenados com o conteúdo da tarefa nada representam, é fonte geradora de enorme aumento da carga psíquica e, conseqüentemente, de maior desajuste do apenado. E é justamente aí que deveria residir a maior preocupação da organização penitenciária, uma vez que seu principal objetivo é de reeducar os apenados por meio do trabalho.

A categoria do trabalho prisional no desenvolvimento pessoal baseou-se na sincronia entre as informações obtidas nas entrevistas e o entendimento de Dejours (1992) referente à intermediação do trabalho no engajamento dos indivíduos nas relações sociais. Esses transferem as questões herdadas de seu passado e de sua história afetiva para as relações sociais; dessa forma, a ressonância simbólica aparece como condição necessária para uma articulação bem sucedida da dicotomia singular com a sincronia coletiva.

Para o estabelecimento da ressonância simbólica são necessárias três condições básicas: a escolha profissional; a atividade de elaboração na tarefa; e uma terceira que está ligada ao caráter coletivo do trabalho em situação real. A sublimação implica uma troca de parceiros, o parceiro da sublimação está inteiramente situado no espaço social e não mais no espaço privado. A sublimação é atividade útil e socialmente valorizada, o que pressupõe um julgamento pronunciado por alguém. O julgamento só pode ter sentido, se for pronunciado pelos parceiros que possuem competência para julgar a qualidade do trabalho. Submetendo seu trabalho a críticas, o sujeito espera receber em troca reconhecimento. O reconhecimento é a retribuição fundamental da sublimação; isso significa que essa tem papel importante na conquista da identidade. Reconhecimento social e identidade como condição de sublimação conferem à sublimação uma função essencial na saúde mental e, conseqüentemente, no desenvolvimento pessoal dos indivíduos.

À luz desse entendimento, os dados obtidos nas entrevistas referentes ao trabalho prisional nos levam a sérias constatações: a instituição penitenciária preconiza a ressocialização por meio do trabalho; mas, observando a forma como ela organiza esse trabalho, percebe-se, sem maiores esforços, que essa não possui nenhuma das condições para que o apenado, mediante o trabalho prisional, consi- 
ga estabelecer a ressonância simbólica e, conseqüentemente, a sublimação; o trabalho prisional não chega a atingir nenhuma das condições necessárias para promover a ressonância simbólica; pelo contrário, as três condições necessárias para seu estabelecimento são percebidas como fatores contrários às normas de disciplina.

Dessa maneira, entende-se que o trabalho prisional atual não possui a menor condição de ressocialização; longe de promover o desenvolvimento pessoal, submete os apenados à situação de excessivo desgaste emocional, e, conseqüentemente, aumenta o seu desequilíbrio psíquico, levando-os cada vez mais a se afastar das condições necessárias ao seu ajustamento social.

A categoria das condições do trabalho prisional originou-se a partir da concepção de Dejours (1994). O autor assevera que por condições de trabalho se devem entender as pressões físicas, mecânicas, químicas e biológicas do posto de trabalho. As pressões ligadas às condições de trabalho têm por alvo principal o corpo dos trabalhadores, onde elas podem ocasionar desgaste, envelhecimento e doenças.

O autor ainda refere que por organização do trabalho devemos entender, por um lado, a divisão do trabalho: divisão de tarefas entre operadores, repartição, cadência e o modo operatório prescrito e, por outro lado, a divisão de homens: repartição das responsabilidades, hierarquia, comando, controle. A divisão de homens é complemento da divisão do trabalho.

As condições de trabalho têm por alvo, principalmente, o corpo do indivíduo. Já na organização do trabalho, o alvo é o aparelho psíquico. A divisão das tarefas e o modo operatório incitam o sentido e o interesse do trabalho ao sujeito, enquanto a divisão de homens solicita, sobretudo, as relações entre pessoas e mobiliza os investimentos afetivos, amor e o ódio, a amizade, a solidariedade, a confiança.

Portanto o trabalho prisional, para promover a ressocialização, deve, obrigatoriamente, levar em conta a combinação dos elementos da divisão de tarefas e do modo operatório, bem como da divisão de homens. Somente assim se pode prever o impacto, positivo ou não, que o trabalho possa vir a ter sobre a saúde dos apenados e suas conseqüências diretas no processo de ressocialização.

A administração penitenciária tem de levar em conta que, para penetrar no campo trabalho-saúde mental, é necessário considerar, antes de tudo, as relações sociais. O indivíduo é visto dentro destas relações sob duplo enfoque: o dos procedimentos defensivos contra o sofrimento do trabalho (que justamente articulam as produções deste indivíduo àquela do coletivo); e o da ressonância simbólica (que articula o teatro privado da história singular do sujeito ao teatro atual e público do 
trabalho); abre-se assim, uma problemática socialmente referenciada da sublimação e do prazer no trabalho. Quanto à organização do trabalho, a administração penitenciária deve entender que ela constitui uma relação socialmente construída, e não somente baseada nos preceitos da LEP, aliados aos preceitos das instituições totais.

Tendo como objeto central deste estudo a compreensão da inoperância do atual modelo de trabalho prisional, utilizado pelo sistema penitenciário de nosso Estado, podemos agora dizer que o trabalho prisional realmente constitui fator de ressocialização, à medida que o trabalho representa fator de equilíbrio. Por meio dele os indivíduos garantem equilíbrio e melhor condicionamento psicológico, bem como melhor comprometimento social. Portanto o trabalho assume importância capital, na construção da identidade, e, ainda, é por ele que os indivíduos conseguem dar vazão a sua epistemofilia no traçar a sua história afetiva.

Porém, para que esse processo se efetive, a administração penitenciária deve compreender que na relação do indivíduo com o trabalho perpassam dois traços característicos de todos os seres humanos: a ação e a reflexão. Dessa forma, para atingirem os níveis de consciência necessários à ressocialização, os apenados não podem e não devem ser reduzidos a um organismo submetido ao bombardeamento de estímulos restritores.

Ao organizar o processo de trabalho prisional, a administração penitenciária deve, antes de tudo, entender que o indivíduo é também um ser de desejo, de pulsão e de relação. E é por meio das relações mantidas entre os indivíduos que eles vêem seus desejos e sua existência reconhecidos ou não.

O universo humano é um mundo de signos, de imagens, de metáforas e de símbolos. Juntamente com a sociedade, os seres humanos produzem uma representação do mundo que lhes confere significação. A imaginação simbólica busca representar para si, antes de mais nada, o ausente, o imperceptível, o indescritível. Mais ou menos arbitrárias, estas representações simbólicas, que calcam sua existência nas relações com o mundo, vão participar da construção deste universo de significações inerentes ao ser humano.

A organização, enquanto espaço particular da experiência humana, é lugar propício à emergência do simbólico. Este simbólico é marcado por uma tensão característica das sociedades industrializadas em que, de um lado, existe a razão econômica que reduz a significação atribuída ao trabalho e, de outro, aparece a existência humana na procura ininterrupta do simbólico (Chanlat, 1992).

A administração penitenciária corrobora essa assertiva, à medida que visa a ressocializar indivíduos pelo trabalho prisional. No entanto organiza seu trabalho 
como uma instituição total, onde não há possibilidade de emergência do simbólico; pelo contrário, parece haver incessante preocupação em destruir tudo o que se reporta ao imaginário, ao simbólico.

O trabalho prisional atualmente desenvolve-se de forma prescrita e rigidamente estabelecida pela legislação, que se baseia nos princípios tayloristas de administração. A organização penitenciária ignora o apenado como ser portador de desejos, de aspirações e de projetos. Conseqüentemente, ignora o apenado como ser simbólico; baseando a forma de organização do trabalho em disciplina e segurança, faz com que o apenado desenvolva suas atividades de maneira autoritária, não lhe permitindo fazer nenhuma modificação ou rearranjo nas tarefas, de maneira a adequá-lo às suas necessidades fisiológicas ou aos seus desejos psicológicos. Dessa forma, carrega a falta de conteúdo da tarefa, que não lhe permite uma satisfação sublimatória.

Assim, o apenado passa a ter com o trabalho uma relação de sofrimento, que não permite a fantasia, a imaginação, não tendo oportunidade de transformar esse sofrimento em um sofrimento criativo.

Criam-se indivíduos alienados, que confundem seus desejos próprios com os da organização, o que substitui seu livre arbítrio, possibilitando à instituição manter seus valores de disciplina e de segurança, mas longe de gerar as condições necessárias à ressocialização, uma vez que sua dimensão organizacional está mais propícia ao descompasso psíquico dos apenados do que a torná-los indivíduos capazes de discernimento entre as suas vontades e as dos outros.

Não se afirma que a administração penitenciária não deva privilegiar a disciplina e a segurança nos presídios. Tenta-se, apenas, alertar para o fato de que, ao pensar em ressocialização, estes fatores não devem ser os únicos ou os principais de um processo ressocializador.

Salienta-se também que, embora o trabalho constitua fator de equilíbrio e de condicionamento social e, portanto, fator de ressocialização, as conseqüências positivas advindas dele passam, obrigatoriamente, pela relação entre prazer e sofrimento. Assim, o real significado do trabalho, para a construção dos indivíduos, só virá à tona à medida que forem estabelecidas essas relações, e haja espaço para que os indivíduos encontrem formas de transformar o sofrimento em prazer.

Dessa forma, chega-se à conclusão de que a inoperância do atual modelo ressocializador provém da maneira como é organizado o trabalho prisional, que não permite ao apenado possuir condições de se engajar nas relações sociais nem de transferir as questões herdadas de sua história afetiva.

Portanto, ao pensar em ressocialização de apenados, em gerar estratégias de 
ressocialização por meio do trabalho prisional, deve-se, principalmente, reorganizar toda a forma como é utilizado o trabalho prisional. Ao organizá-lo, a instituição deve buscar um tipo de trabalho mais criativo, mais flexível, objetivando sempre a interação entre as necessidades dos apenados e o conteúdo da tarefa, de maneira que esse logre sentir-se como um indivíduo portador de desejos, de aspirações e de fantasias, como ser simbólico, em ambiente organizacional que dissocie o criminoso do crime.

Esperamos que o presente estudo possa dar uma contribuição, mesmo que pequena, à compreensão de como o trabalho prisional deva ser organizado, para atender seus objetivos ressocializadores, sempre passando pela relação entre prazer e sofrimento no trabalho.

Sabe-se, no entanto, que esta pesquisa deveria ser feita em maior número de presídios, pois se reconhece que sua validade é mais interna do que externa. Embora tenha esse limite interno, o presente trabalho é uma pesquisa descritiva, que proporcionou conhecer uma determinada realidade e, ao mesmo tempo, ofereceu condições para que fossem feitas determinações.

Dessa forma, pode-se sugerir, por meio do conhecimento dessa realidade que, para proceder a uma reforma na atual organização do trabalho prisional, em que se possam atingir índices mais elevados de ressocialização, deveriam existir estudos referentes às reais condições do corpo funcional do sistema penitenciário, analisando a forma como percebem o trabalho prisional. Deveria ser feita também uma reavaliação da Lei de Execuções Penais. E, ainda, estudos no sentido de conscientizar a sociedade do seu papel nesse processo de ressocialização: não adianta reorganizar o trabalho prisional e, por ele, capacitar o indivíduo ao convívio social, se a própria sociedade continua a negá-los.

\section{ReFERÉnCias Biblográficas}

BARDIN, L.

Análise de conteúdo. Lisboa : Edições 70, 1977.

\section{BRASIL.}

Lei ${ }^{\circ}$. 7.210, de 11 de julho de 1984. Institui a Lei de Execução Penal.

\section{CHANLAT, J. F.}

O indivíduo na organização : dimensões esquecidas. São Paulo : Atlas, 1992.
DEJOURS, C.

A loucura do trabalho. 5. ed. São Paulo : Cortez-Oboré, 1992.

DEJOURS, C.; ABDOUCHELI, E.; JAYET, $C$.

Psicodinâmica do trabalho Contribuições da escola dejouriana à análise da relação prazer, sofrimento e trabalho. São Paulo: Atlas, 1994. 
DEJOURS, C.;

DESSORS, D.;

DESRIAUX, F.

Por um trabalho, fator de equilíbrio. Revista de Administração de Empresas, mai./jun. 1993.

FOUCAULT, $\mathrm{M}$.

Vigiar e punir - história da violência nas prisões. Rio de Janeiro : Vozes, 1975.

Microfísica do poder. 8. ed. Rio de Janeiro : 1989.

GAJ, L.

Tornando a administração estratégica possível. São Paulo : McGraw-Hill, 1990.

GOFFMANN, E.

Manicômios, prisões e conventos. São Paulo : Perspectiva, 1974.

MELOSSI, D.;

PAVARINI, $\mathrm{M}$.

Cárcere y fábrica: los orígenes del sistema penitenciario. México : Siglo Veintiuno, 1987.
ORGANIZAÇÃO DAS NAÇÕES UNIDAS.

Regras mínimas para o tratamento de presos e procedimentos para aplicação efetiva das regras. Nova York, 1984.

PAGÉS, M. et al.

O poder das organizações. São Paulo : Atlas, 1992.

RAGO, L. M.;

MOREIRA, E. F. P.

O que é taylorismo. 5. ed. São Paulo : Brasiliense, 1984.

RIO GRANDE DO SUL.

Lei $n^{\circ}$. 5.745, de 28 de dezembro de 1968. Dispõe sobre a estrutura da Superintendência dos Serviços Penitenciários da Secretaria do Interior e da Justiça e dá outras providências.

WOLFF, M. P.

Prisões no Rio Grande do Sul : aspectos de sua evolução e problemática. Porto Alegre, 1990. Dissertação (Mestrado em Serviço Social) - Pontifícia Universidade Católica do Rio Grande do Sul. 